This item was submitted to Loughborough's Research Repository by the author.

Items in Figshare are protected by copyright, with all rights reserved, unless otherwise indicated.

\title{
Decoupling control of electrified turbocharged diesel engines
}

PLEASE CITE THE PUBLISHED VERSION

http://dx.doi.org/10.1109/ACC.2016.7525583

\section{PUBLISHER}

(c) AACC (American Automatic Control Council). Published by IEEE.

\section{VERSION}

AM (Accepted Manuscript)

\section{PUBLISHER STATEMENT}

This work is made available according to the conditions of the Creative Commons Attribution-NonCommercialNoDerivatives 4.0 International (CC BY-NC-ND 4.0) licence. Full details of this licence are available at: https://creativecommons.org/licenses/by-nc-nd/4.0/

\section{LICENCE}

CC BY-NC-ND 4.0

\section{REPOSITORY RECORD}

Zhao, Dezong, Edward Winward, Zhijia Yang, Richard Stobart, and Thomas Steffen. 2017. "Decoupling Control of Electrified Turbocharged Diesel Engines". figshare. https://hdl.handle.net/2134/24352. 


\title{
Decoupling Control of Electrified Turbocharged Diesel Engines
}

\author{
Dezong Zhao, Member, IEEE, Edward Winward, Zhijia Yang, Richard Stobart, Member, IEEE, \\ and Thomas Steffen
}

\begin{abstract}
Engine electrification is a critical technology in the promotion of engine fuel efficiency, among which the electrified turbocharger is regarded as a promising solution for its advantages in engine downsizing and exhaust gas energy recovery. By installing electrical devices on the turbocharger, the excess energy can be captured, stored, and re-used. The control of the energy flows in an electrified turbocharged diesel engine (ETDE) is still in its infancy. Developing a promising multi-input multi-output (MIMO) control strategy is essential in exploring the maximum benefits of electrified turbocharger. In this paper, the dynamics in an ETDE, especially the couplings among multiple loops in the air path are analyzed. Based on the analysis, a model-based MIMO decoupling control framework is designed to regulate the air path dynamics. The proposed control strategy can achieve fast and accurate tracking on selected control variables and is successfully validated on a physical model in simulations.
\end{abstract}

\section{INTRODUCTION}

Motivated by the increasing pressure on fuel consumption and environmental protection, stricter fuel efficiency legislations are made on vehicles globally. In European Union countries, the fuel consumption of passenger cars and vans are required to curb the $\mathrm{CO}_{2}$ emissions from $130 \mathrm{~g} / \mathrm{km}$ in 2015 to $95 \mathrm{~g} / \mathrm{km}$ in 2020 . In parallel, the fuel efficiency standards on heavy-duty vehicles (HDVs) are also being designed [1]. The HDVs contribute almost one quarter of the fuel consumption in transportation, and most of which are equipped with diesel engines due to their high thermal efficiency and high torque at low speeds [2]. Studies carried out suggest that the most potential techniques in vehicle fuel consumption reduction are engine efficiency improvement and engine hybridization [3]. Electified turbocharger is a critical technology in engine electrical hybridization. The electrified turbocharger consists of a variable geometry turbocharger (VGT) and an electric motor (EM) within the turbocharger bearing housing. The EM is capable in bi-directional power transfer, and therefore, the VGT and the EM both have the ability to manage the energy flows in the air path. When the turbine power exceeds the required compressor power, the extra mechanical power is recuperated by the EM to power other electrical accessories or stored in battery for later usage. On the other hand, when the available turbine power is less than the required compressor power, the EM accelerates the turbocharger to assist boosting. Considering

D. Zhao, Z. Yang, R. Stobart, and T. Steffen are with Department of Aeronautical and Automotive Engineering, Loughborough University, Loughborough, Leicester, UK (e-mail: d.zhao2@lboro.ac.uk, z.yang2@lboro.ac.uk, r.k.stobart@lboro.ac.uk, t.steffen@lboro.ac.uk).

E. Winward is with Energy and Transportation Research, Caterpillar Inc., Peterborough, UK. a third of fuel energy in internal combustion engines (ICE) is lost to the environment through the exhaust gas [4], the electrified turbocharger is seen as a promising solution in raising fuel efficiency of HDVs [5].

The electrified turbocharger has attracted considerable development interest. Advances in power electronics have led to the development of ultra-high speed EM with the capacity of higher than $100,000 \mathrm{rpm}$, which is now available for use in turbochargers [6], [7]. The mainstream diesel engine and turbocharger manufacturers have developed their own prototype electrified turbochargers [8]-[10]. Investigations on the efficiency mapping of an electrified turbocharger with a heavy-duty diesel engine have been made in [11]-[15]. The current research all suggest that the development of a promising multi-input multi-output (MIMO) dynamic control strategy on electrified turbocharged diesel engines (ETDE) is required.

The control of the ETDE is still in the early age. In [10], the EM is controlled in an open loop manner. In [16], the EM, VGT, and exhaust gas recirculation (EGR) valve are controlled independently without considering the couplings. In 2014, a consortium led by Caterpillar Inc. developed a cutting-edge electrified turbocharger called electric turbo assist (ETA). Based on the ETA, several control methods and testing systems were developed in Loughborough University in simulations [17]-[19] and experiments [20]-[23]. This paper analyzes the dynamics of the ETDE. Furthermore, a model-based MIMO decoupling control strategy is proposed.

The paper is organized as follows. After the introduction in section I, the ETDE model is described in section II. The control-oriented dynamics is analyzed in section III. The controller design is presented in section IV. Validation results of the strategy are demonstrated in section V. Finally, the conclusions are summarized in section VI.

\section{Electrified Turbocharged Diesel Engine MODEL}

In Table I, the variables and related parameters of the ETDE illustrated in Fig. 1 are listed. A switched reluctance motor (SRM) is selected as the EM for it is an excellent option in extra-high speed applications thanks to its simple structure [24]. The EM can work in both assist mode and generator mode. In assist mode, the EM extracts energy from the battery to improve the engine transient response, or provide steady state boost pressure to enhance low speed torque. In generator mode, the additional turbine torque resulting from exceed exhaust energy causes a power flow to the generator. 


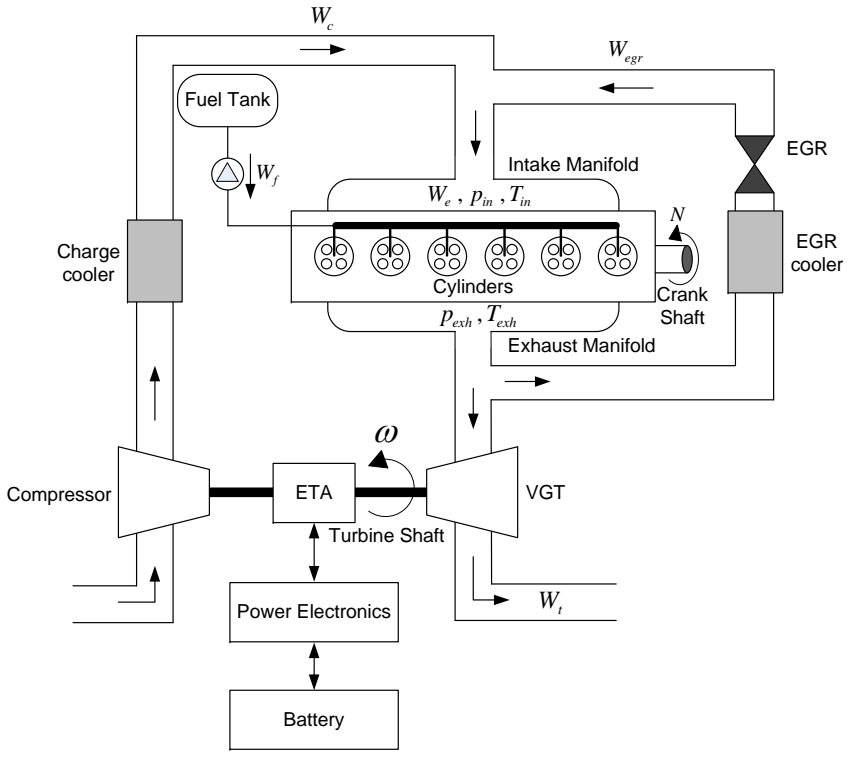

Fig. 1. Electrified turbocharged diesel engine

TABLE I

NOMENCLATURE

\begin{tabular}{lll}
\hline Variable & Description & $\mathrm{Unit}$ \\
\hline$N$ & Engine speed & $\mathrm{rpm}$ \\
$T_{L}$ & Engine load & $\mathrm{Nm}$ \\
$W_{f}$ & Engine fuelling rate & $\mathrm{kg} / \mathrm{s}$ \\
$W_{c}$ & Compressor air mass flow rate & $\mathrm{kg} / \mathrm{s}$ \\
$W_{e g r}$ & EGR mass flow rate & $\mathrm{kg} / \mathrm{s}$ \\
$W_{e}$ & Engine total mass flow rate & $\mathrm{kg} / \mathrm{s}$ \\
$W_{t}$ & Turbine gas mass flow rate & $\mathrm{kg} / \mathrm{s}$ \\
$F_{1}$ & Burnt gas fraction, defined as $\frac{W_{e g r}}{W_{c}+W_{e g r}}$ & - \\
$\lambda$ & In-cylinder air-fuel ratio, defined as $\frac{W_{c}}{W_{f}}$ & - \\
$P_{c}$ & Compressor power & $\mathrm{kW}$ \\
$P_{t}$ & Turbine power & $\mathrm{kW}$ \\
$P_{\text {em }}$ & EM power & $\mathrm{kW}$ \\
$p_{i n}$ & Intake manifold pressure & $\mathrm{kPa}$ \\
$p_{\text {exh }}$ & Exhaust manifold pressure & $\mathrm{kPa}$ \\
$p_{a m}$ & Ambient pressure & $\mathrm{kPa}$ \\
$T_{i n}$ & Intake manifold temperature & $\mathrm{K}$ \\
$T_{e x h}$ & Exhaust manifold temperature & $\mathrm{K}$ \\
$T_{a}$ & Ambient temperature & $\mathrm{K}$ \\
$\omega$ & Turbine speed & $\mathrm{rpm}$ \\
$\tau$ & Turbocharger time constant & $\mathrm{s}$ \\
$\eta_{c}$ & Compressor isentropic efficiency & - \\
$\eta_{t}$ & Turbine isentropic efficiency & - \\
$\eta_{m}$ & Turbocharger mechanical efficiency & - \\
$\eta_{v}$ & Volumetric efficiency & - \\
$\chi_{e g r}$ & EGR valve position & - \\
$\chi_{v g t}$ & VGT vane position & - \\
$c_{p}$ & Specific heat at constant pressure, 1.01 & $\mathrm{~kJ} /(\mathrm{kgK})$ \\
$c_{v}$ & Specific heat at constant volume, 0.718 & $\mathrm{~kJ} /(\mathrm{kgK})$ \\
$R_{g}$ & Specific gas constant, $c_{p}-c_{v}$ & $\mathrm{~kJ} /(\mathrm{kgK})$ \\
$\gamma$ & Specific heat ratio, $c_{p} / c_{v}$ & - \\
$\mu$ & $(\gamma-1) / \gamma$ & - \\
\hline & &
\end{tabular}

\section{A. Electrified Turbocharger Model}

The dynamics of the turbocharger can be modeled as a first-order lag power transfer function with time constant $\tau$ :

$$
\dot{P}_{c}=\frac{1}{\tau}\left(P_{t}+P_{e m}-P_{b l}-P_{w l}-P_{c}\right),
$$

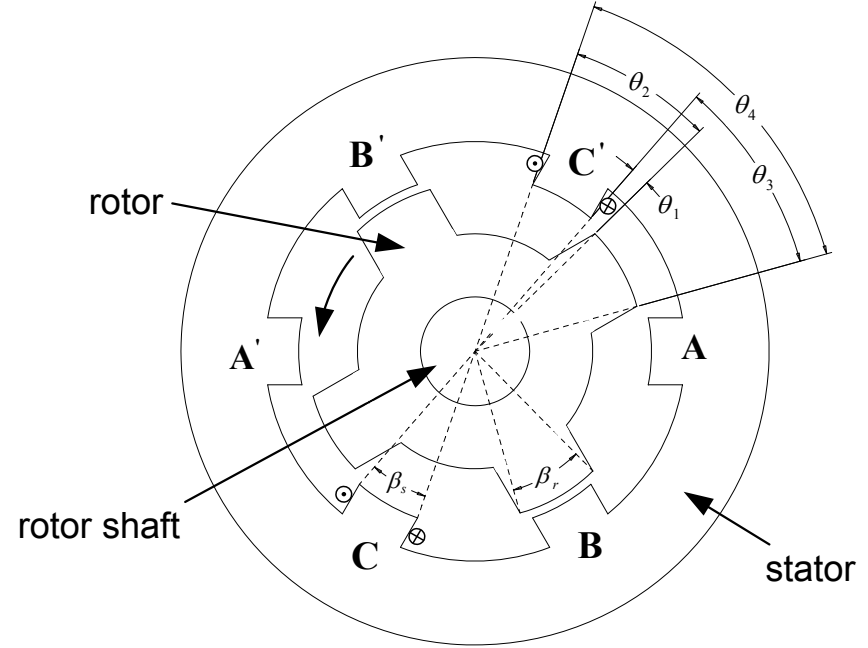

(a) Cross section of a $6 / 4 \mathrm{SRM}$ (phase $B-B^{\prime}$ is at aligned position)

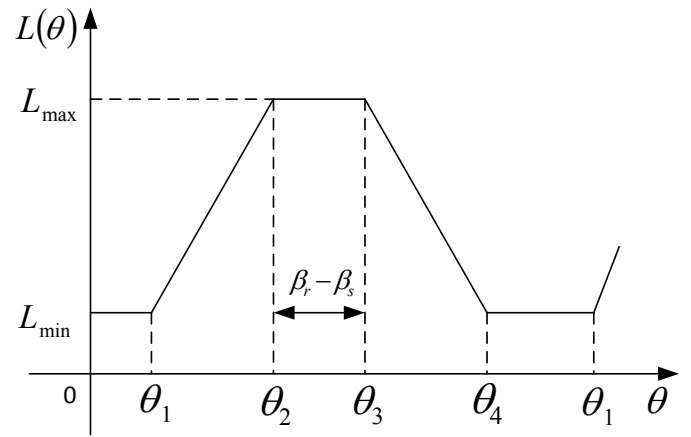

(b) Inductance profile at changing rotor poles angle

Fig. 2. SRM structure and inductance generation

where $P_{b l}$ and $P_{w l}$ are the power to overcome bearing losses and windage losses, respectively. The mechanical efficiency $\eta_{m}$ is introduced to quantify the energy losses. Therefore, (1) can be represented as

$$
\dot{P}_{c}=\frac{1}{\tau}\left(\eta_{m}\left(P_{t}+P_{e m}\right)-P_{c}\right) .
$$

$W_{c}$ is related to $P_{c}$ by

$$
W_{c}=\frac{\eta_{c}}{c_{p} T_{a}} \frac{P_{c}}{\left(\frac{p_{i n}}{p_{a m}}\right)^{\mu}-1},
$$

and $P_{t}$ can be expressed by $W_{t}$ :

$$
P_{t}=\eta_{t} c_{p} T_{e x h}\left(1-\left(\frac{p_{a m}}{p_{\text {exh }}}\right)^{\mu}\right) W_{t} .
$$

\section{B. Electric Motor Model}

A SRM is employed as the EM. The SRM can sustain a high operating temperature since there are no magnets in the rotor. The torque production is concentrated in the period when inductance is maximized at the point the rotor poles align with the excited stator poles. Fig. 2 is an example of the SRM structure with 6 stator poles and 4 rotor poles and an ideal linear inductance profile when phase $C-C^{\prime}$ is excited with constant current for a 6/4 SRM. In Fig. 2(a), $\beta_{s}$ and $\beta_{r}$ denote the pole-arc of stator and rotor, respectively. The 
rotor poles are attracted to align with phase $C-C^{\prime}$ since the inductance is higher in steel than in the air gap. The angle between the rotor and stator poles is denoted as $\theta$. The baseline rotor poles angle is set as 0 , and $\theta_{1}$ is the angle where the overlapping of stator and rotor poles occur. The induction profile is illustrated in Fig. 2(b).

The voltage equation across the terminals of a phase of SRM windings is:

$$
V=R_{s} i+\frac{\mathrm{d} \Psi(\theta, i)}{\mathrm{d} t},
$$

where $V$ and $i$ are the terminal voltage and phase current respectively, $R_{s}$ is the winding resistance, and $\Psi(\theta, i)$ is the winding flux linkage. In the ideal case, the flux linkage and the current have the following relationship:

$$
\Psi(\theta, i)=L(\theta) i
$$

The electromagnetic torque generated by the SRM is given by [25]

$$
T_{e}(\theta, i)=\frac{1}{2} i^{2} \frac{\mathrm{d} L(\theta)}{\mathrm{d} \theta} .
$$

In the ETA, the turbine shaft is the SRM rotor shaft, so the EM power introduced in (1) is given by

$$
P_{e m}=T_{e}(\theta, i) \omega .
$$

\section{Control-Oriented DynAmics AnAlysis}

The key to reducing exhaust emissions in terms of $\mathrm{NO}_{\mathrm{x}}$ and PM is keeping rational values of $F_{1}$ and $\lambda$, which can be obtained from the independent variables $W_{c}$ and $W_{\text {egr }}$ according to the expressions in Table I. The independent variables can also be replaced by $p_{i n}$ and $W_{\text {egr }}$. However, to achieve a more integrated target containing fuel efficiency and exhaust emissions, $p_{i n}$ and $W_{\text {egr }}$ are not enough. Since the EM impacts the exhaust manifold dynamics directly, a performance variable in the exhaust manifold has to be considered.

A criteria in selecting control variables is that they cannot be strongly coupled. The criteria guarantees independent control of selected variables. To analyze the relationship between different control variables, a calibration is implemented on a high fidelity engine simulation platform at $1800 \mathrm{rpm}, 600 \mathrm{Nm}$ by tuning $\chi_{v g t}$ and $P_{e m}$. The results with no EGR are illustrated in Fig. 3. The setting on $\chi_{v g t}$ and $P_{e m}$ is shown as Fig. 3(a), where $P_{e m}$ changes from the maximum generating power to the maximum motoring power, with the value of $-5 \mathrm{~kW}$ and $5 \mathrm{~kW}$, respectively. The $\chi_{v g t}$ changes from 0.1 to 0.9 , where 0 implies the VGT vane is fully closed and offers the maximum assistance to the compressor. Fig. 3(b) shows the strong coupling between boost pressure and turbine speed. The turbine speed behaves as a 2nd-order polynomial function with the boost pressure, which shows the strong coupling between them. However, the strong coupling also implies the turbine speed can be shifted by the EM in transients to obtain the most efficient boost [13]. On the other hand, the exhaust pressure varies much according to different settings on $\chi_{v g t}$, as shown in Fig. 3(c). With the VGT vane closing from 0.9 to 0.1 , both

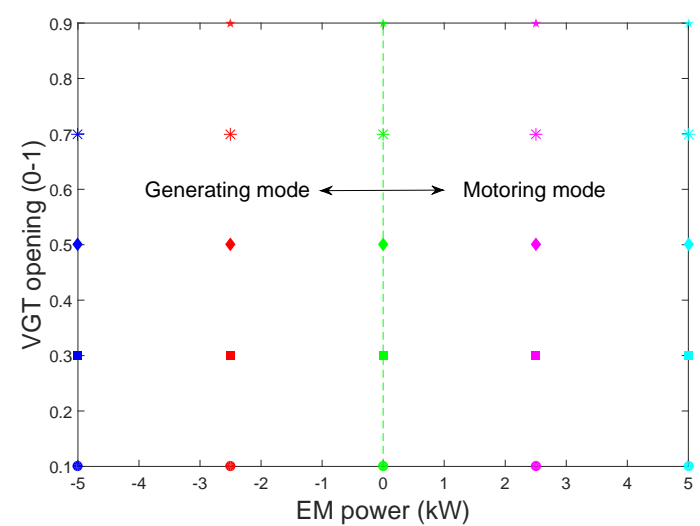

(a) The setting on $\chi_{v g t}$ and $P_{e m}$

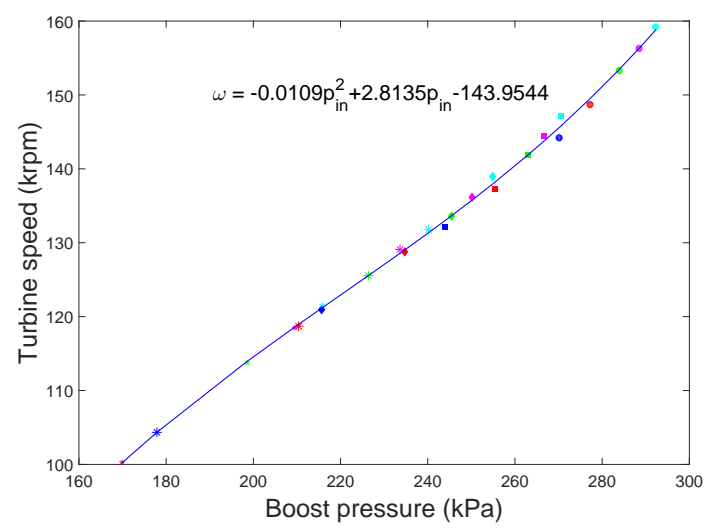

(b) Fitting polynomial between $p_{i n}$ and $\omega$

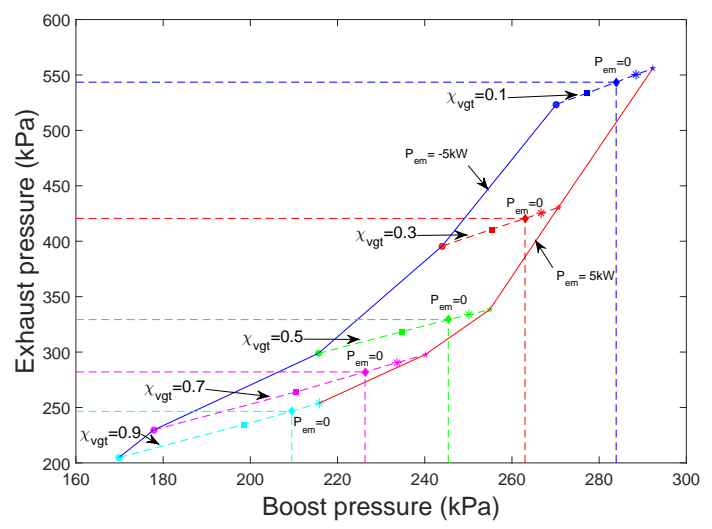

(c) Calibration data on $p_{i n}$ and $p_{e x h}$

Fig. 3. Calibration data by regulating $\chi_{v g t}$ and $P_{e m}$

boost pressure and exhaust pressure increase, as well as the condition when $P_{e m}$ increases with the fixed $\chi_{v g t}$.

The coupling between boost pressure and turbine speed can also be found using a theoretical causality analysis. Suppose a 2 inputs - 2 outputs control structure, where $p_{i n}$ and $\omega$ are controlled by $\chi_{v g t}$ and $P_{e m}$, respectively. If the desired turbine speed $\omega^{*}$ increases, $P_{e m}$ would increase accordingly to drive up $\omega$. At the mean time, $p_{\text {in }}$ would be driven up because of the enhanced boost assist. To keep the tracking on unchanged $p_{i n}^{*}, \chi_{v g t}$ would open further to 


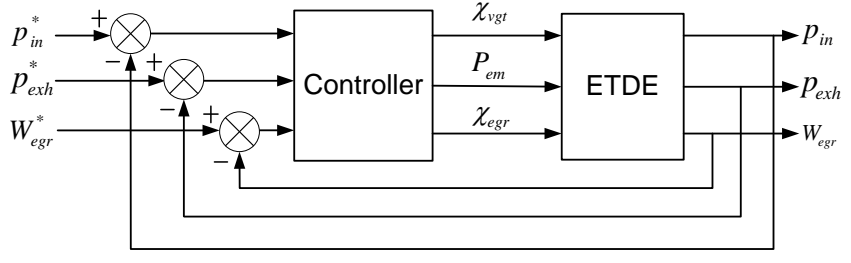

Fig. 4. Control structure of the ETDE

reduce $p_{i n}$. As a result, $\omega$ is decreased for the less pressure ratio in exhaust manifold. Therefore, $\omega$ has a strong coupling with $p_{i n}$ and its setpoint cannot be selected independently. Based on both test results and dynamics analysis, $p_{\text {exh }}$ is selected as the control variable, together with $p_{i n}$ and $W_{e g r}$.

\section{Decoupling Controller Design}

The single-input single-output (SISO) PI controllers are widely used in the control of conventional turbocharged diesel engines, while $p_{i n}$ and $W_{\text {egr }}$ are controlled by $\chi_{v g t}$ and $\chi_{\text {egr }}$, respectively. The gain values of PI controllers are tuned in off-line calibration. However, in the ETDE, the dynamics has been significantly changed, therefore the controllers are to be re-designed. Since it is time-consuming to re-tune the gain values manually, designing a decoupling MIMO controller is critical. The control inputs and measured outputs are selected as

$$
\begin{aligned}
& u=\left[\begin{array}{lll}
\chi_{v g t} & P_{\text {em }} & \chi_{\text {egr }}
\end{array}\right]^{\mathrm{T}}, \\
& y=\left[\begin{array}{lll}
p_{\text {in }} & p_{\text {exh }} & W_{\text {egr }}
\end{array}\right]^{\mathrm{T}} .
\end{aligned}
$$

The 3-inputs 3-outputs control structure of the ETDE is illustrated as Fig. 4.

The ETDE model is formed by the state space equations:

$$
\left[\begin{array}{c}
\dot{x} \\
z \\
y
\end{array}\right]=\left[\begin{array}{ccc}
A & B_{1} & B_{2} \\
C_{1} & D_{11} & D_{12} \\
C_{2} & D_{21} & D_{22}
\end{array}\right]\left[\begin{array}{c}
x \\
w \\
u
\end{array}\right],
$$

where $x \in \mathbb{R}^{n}$ is the state vector, $u \in \mathbb{R}^{m_{2}}$ is the vector of control inputs, $w \in \mathbb{R}^{m_{1}}$ is the vector of exogenous inputs, $y \in \mathbb{R}^{p_{2}}$ is the vector of measured outputs, $z \in \mathbb{R}^{p_{1}}$ is the vector of regulated outputs. In the proposed ETDE control, $w$ and $z$ are defined as

$$
w=\left[\begin{array}{ll}
\Delta N, & \Delta T_{L}
\end{array}\right]^{\mathrm{T}}
$$

and

$$
z=\left[\begin{array}{lll}
\Delta p_{i n}, & \Delta p_{\text {exh }}, & \Delta W_{\text {egr }}
\end{array}\right]^{\mathrm{T}},
$$

where $\Delta N$ and $\Delta T_{L}$ denote the disturbances on $N$ and $T_{L}$; $\Delta p_{i n}, \Delta p_{e x h}, \Delta W_{e g r}$ denote the variations on $p_{i n}, p_{e x h}$, and $W_{\text {egr }}$ introduced by $w$, respectively.

A nonsmooth $H_{\infty}$ synthesis method is employed to build $u$ since it is very convenient in practice [26]. This method can address a mixed set of time- and frequency- domain criteria including settling time, steady state error, stability margin, and noise rejection. The constraints can be grouped as hard (must have) constraints and soft (nice to have) objectives.

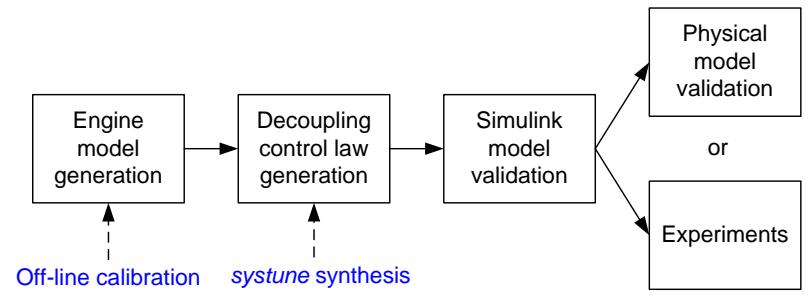

Fig. 5. Workflow in developing decoupling controller for the ETDE

The controller synthesis is transformed to an optimization problem as

$$
\begin{array}{ll}
\underset{g}{\operatorname{minimize}:} & \max _{i}\left\{\left\|T_{w_{i} \rightarrow z_{i}}(P, K)\right\|\right\}, \\
\text { subject to : } & \max _{j}\left\{\left\|T_{w_{j} \rightarrow z_{j}}(P, K)\right\|\right\} \leq 1,
\end{array}
$$

where $g$ is the vector of tunable gain values, $\left\|T_{w \rightarrow z}\right\|$ denotes the closed loop map from input $w$ to output $z$, and $\|\cdot\|$ can be either $H_{\infty}$ norm or $H_{2}$ norm, $i$ and $j$ denote the index of soft objectives and hard constraints, respectively. The optimization problem (13) and (14) means to minimize the worst-case value of the soft objectives while satisfying all the hard constraints. In the formulation, all terms have been normalized.

In this research, the soft objectives are settling time and steady state error. The hard constraints are stability margins including the gain margin and phase margin. The coefficient matrices in (10) are obtained via calibration tests. The systune solver in Matlab is adopted to compute the decoupling control law.

\section{Simulation Results}

Simulations have been carried out on a physical plant model built in Dynasty, a proprietary multi physics simulation software package used within Caterpillar. The engine manifolds are modeled as one-dimensional components, permitting to capture the pulsations caused by engine actuators operation. All the cylinders are modeled separately to indicate the energy transfer from engine to turbocharger, such that the transient performance is simulated accurately.

The EM, compressor and turbine are all represented as map based models. The controllers are built in Matlab/Simulink for the available tools in Matlab can facilitate the controller design. To guarantee steady communications, the sampling frequency of the controller in Matlab and the controlled plant in Dynasty are set as identical. The investigated engine is a six-cylinder, 7.01-L heavy-duty engine with rated power of $225 \mathrm{~kW}$ at $2200 \mathrm{rpm}$ and a rated torque of $1280 \mathrm{Nm}$ at $1400 \mathrm{rpm}$. The engine is fitted with an experimental turbocharger. The maps used in the paper are all generated from off-line experimental calibration on the instrumented engine.

Prior to the physical simulation, the decoupling control law has been validated in the Simulink model, while the engine model is built from the off-line engine calibration data. Generally speaking, the workflow of this paper can be illustrated as Fig. 5. The simulations on Simulink and 

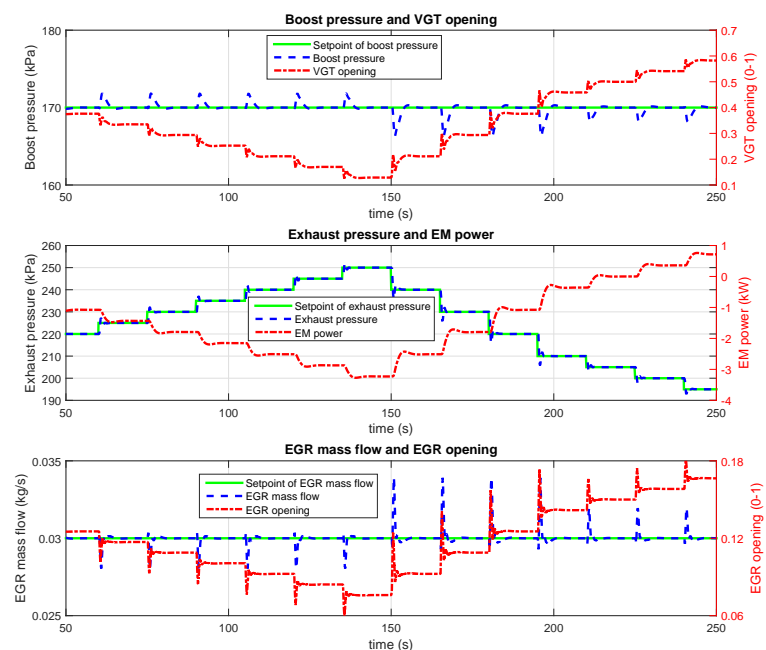

Fig. 6. Simulation results at $1800 \mathrm{rpm}, 260 \mathrm{Nm}$ in Simulink

Dynasty are both implemented. The operating points are selected as $1800 \mathrm{rpm}, 260 \mathrm{Nm}$, and $1800 \mathrm{rpm}, 815 \mathrm{Nm}$, covering the low load region and high load region, which are typical working conditions in the trenching test cycle for heavy-duty engines. A block load condition between the switching of the two operating points is also given, while the gain values are scheduled according to the load.

\section{A. Simulation in Simulink}

In the Simulink simulation, both the controller and the ETDE model are built in Simulink. In generating the decoupling control law, the criteria are to be specified. In the soft objectives, the criteria on settling time and steady state error are set as $1 \mathrm{~s}$ and $0.5 \%$, respectively. In the hard constraints, the criteria on gain margin and phase margin are set as $3 \mathrm{~dB}$
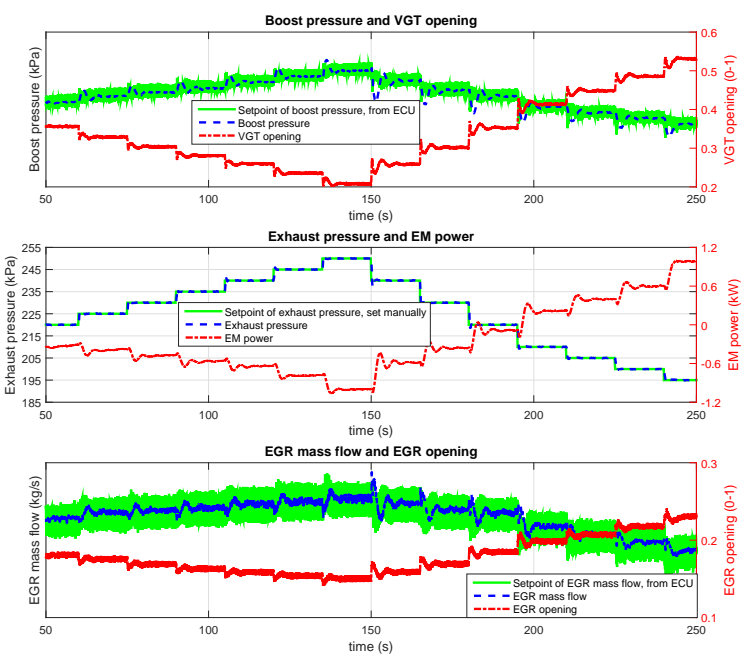

Fig. 7. Simulation results at $1800 \mathrm{rpm}, 260 \mathrm{Nm}$ in Dynasty
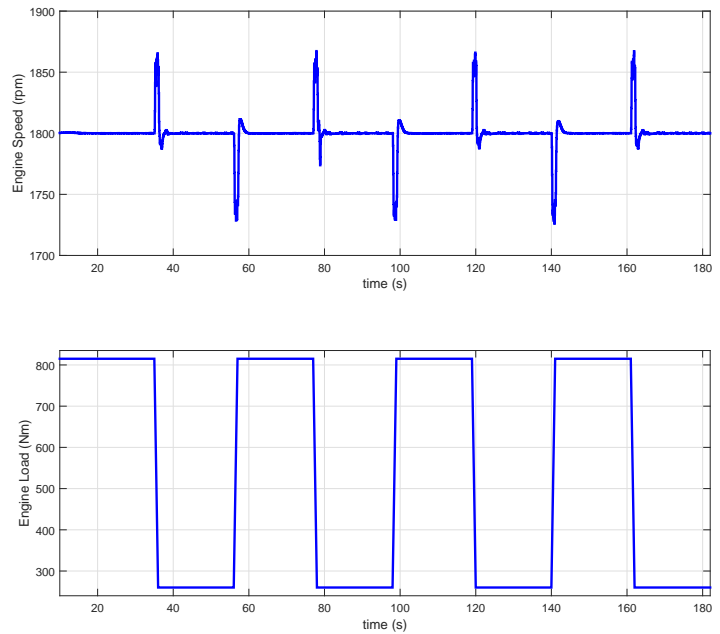

Fig. 8. Operating points at block loads
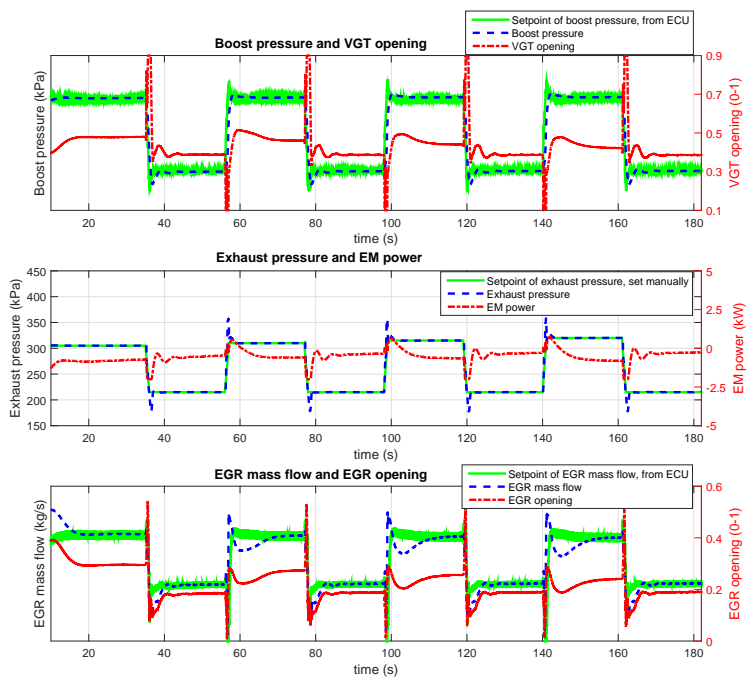

Fig. 9. Simulation results at block loads in Dynasty

and $5 \mathrm{rad} / \mathrm{s}$, respectively. At the operating point of $1800 \mathrm{rpm}$, $260 \mathrm{Nm}$, the setpoints on $p_{i n}$ and $W_{\text {egr }}$ are set as $170 \mathrm{kPa}$ and $0.03 \mathrm{~kg} / \mathrm{s}$, respectively, while the setpoint on $p_{\text {exh }}$ changes as a sequence of step-changed values between $195 \mathrm{kPa}$ and $250 \mathrm{kPa}$. It can be observed from Fig. 6 that the tracking on all the three variables is very fast.

\section{B. Simulation in Dynasty}

In the Dynasty simulation, the controller and ETDE model are built in Simulink and Dynasty, respectively. As a comparison, the simulation results at $1800 \mathrm{rpm}, 260 \mathrm{Nm}$ in Dynasty is illustrated in Fig. 7. The setpoint on $p_{\text {exh }}$ is kept as the same in Simulink simulation. To reveal the engine dynamics better, the setpoints on $p_{i n}$ and $W_{e g r}$ are generated from the embedded setpoints maps in the engine control unit (ECU). The tracking performance is very good. 
The block loads operating condition and the corresponding test results are demonstrated as Fig. 8 and Fig. 9, respectively. The tracking of the control variables in transients is very fast with small spikes, as can be observed in Fig. 9. The employed decoupling controller only need to schedule gain values rather than the system model when operating point changes, which reduces the risk of system instability.

\section{CONCLUSIONS}

A model-based MIMO decoupling controller is designed for the ETDE. In generating the control law, both the requirements on tracking performance and stability margins are considered. The selection of control inputs and control outputs is based on concrete dynamics analysis. Simulation results on both Simulink model and physical model are all given. The designed controller strongly underpin the next stage real-time optimization of fuel economy of ETDE. The next stage work would be the experimental validation of the proposed strategy.

\section{ACKNOWLEDGEMENT}

This work was co-funded by Innovate UK (formerly the Technology Strategy Board UK), under a grant for the Low Carbon Vehicle IDP4 Programme (TP14/LCV/6/I/BG011L). The Innovate UK is an executive body established by the United Kingdom Government to drive innovation. It promotes and invests in research, development and the exploitation of science, technology and new ideas for the benefit of business - increasing sustainable economic growth in the UK and improving quality of life.

Thanks also go to our consortium partners and subcontractors.

\section{REFERENCES}

[1] (2012, July) Heavy-duty vehicle fuel efficiency regulatory developments around the world. [Online]. Available: http://www. theicct.org/sites/default/files/Bandivadekar_Bangalore_july2012.pdf

[2] S. Bilgen, "Structure and environmental impact of global energy consumption," Renewable and Sustainable Energy Reviews, vol. 38, pp. 890-902, 2014.

[3] A. Brown and D. Chapin, Technologies and Approaches to Reducing the Fuel Consumption of Medium- and Heavy-Duty Vehicles. Washington, D.C., US: The National Academies Press, 2010.

[4] R. Stobart and R. Weerasinghe, "Heat recovery and bottoming cycles for SI and CI engines - a perspective," SAE International, pp. 200601-0662, 2006.

[5] R. Martinez-Botas, A. Pesiridis, and M. Yang, "Overview of boosting options for future downsized engines," Science China Technological Sciences, vol. 54, no. 2, pp. 1-14, 2011.

[6] Y. Yamashita, S. Ibaraki, K. Sumida, M. Ebisu, B. An, and H. Ogita, "Development of electric supercharger to facilitate the downsizing of automobile engines," Mitsubishi Heavy Industries Technical Review, vol. 47, no. 4, pp. 7-12, 2010.

[7] J. Bumby, E. Spooner, J. Carter, H. Tennant, G. Mego, G. Dellora, W. Gstrein, H. Sutter, and J. Wagner, "Electrical machines for use in electrically assisted turbochargers," in Proceedings of the Second International Conference on Power Electronics, Machines and Drives, 2004, pp. 344-349.

[8] M. Bailey, "Electrically-assisted turbocharger development for performance and emissions," in Proceedings of the Diesel Engine Emissions Reduction Workshop, 2000, p. 827803.

[9] S. Arnold, C. Balis, P. Barthelet, E. Poix, T. Samad, G. Hampson, and S. Shahed, "Garrett electric boosting systems (EBS) program," Honeywell Turbo Technologies, Rolle, Switzerland, Tech. Rep. DEFC05-00OR22809, June 2005.
[10] S. Ibaraki, Y. Yamashita, K. Sumida, H. Ogita, and Y. Jinnai, "Development of the hybrid turbo, an electrically assisted turbocharger," Mitsubishi Heavy Industries Technical Review, vol. 43, no. 3, pp. 1-5, 2006.

[11] N. Terdich, R. Martinez-Botas, D. Howey, and C. Copeland, "Off-road diesel engine transient response improvement by electrically assisted turbocharging," SAE International, pp. 2011-24-0127, 2011.

[12] N. Terdich and R. Martinez-Botas, "Experimental efficiency characterization of an electrically assisted turbocharger," SAE International, pp. 2013-24-0122, 2013.

[13] N. Terdich, R. Martinez-Botas, A. Romagnoli, and A. Pesiridis, "Mild hybridization via electrification of the air system: Electrically assisted and variable geometry turbocharging impact on an off-road diesel engine," Journal of Engineering for Gas Turbines and PowerTransactions of the ASME, vol. 136, no. 3, p. 031703, 2014.

[14] A. Costall, R. Ivanov, and T. Langley, "Electric turbo assist as an enabler for engine downspeeding," in Proceedings of the ASME Turbo Expo, 2012, pp. 511-521.

[15] A. Costall, R. Ivanov, and T. Langley, "Electric turbo assist: efficient rapid boost for heavy duty diesel engines," in Proceedings of the Conference on Thermo and Fluid Dynamic Processes in Direct Injection Engines, 2012, pp. 1-18.

[16] B. Glenn, D. Upadhyay, and G. Washington, "Control design of electrically assisted boosting systems for diesel powertrain applications," IEEE Transactions on Control Systems Technology, vol. 18, no. 4, pp. 769-778, 2010.

[17] D. Zhao, R. Stobart, G. Dong, and E. Winward, "Real-time energy management for diesel heavy duty hybrid electric vehicles," IEEE Transactions on Control Systems Technology, vol. 23, no. 3, pp. 829$841,2015$.

[18] D. Zhao and R. Stobart, "Systematic control on energy recovery of electrified turbocharged diesel engines," in Proceedings of the 54th IEEE Conference on Decision and Control, 2015, pp. 1527-1532.

[19] D. Zhao, E. Winward, Z. Yang, and R. Stobart, "Real-time optimal energy management of electrified engines," in Proceedings of the 8th IFAC International Symposium on Advances in Automotive Control, 2016.

[20] D. Zhao, C. Liu, R. Stobart, X. Deng, E. Winward, and G. Dong, "An explicit predictive control framework for turbocharged diesel engines," IEEE Transactions on Industrial Electronics, vol. 61, no. 7, pp. 35403552, 2014.

[21] D. Zhao, C. Liu, R. Stobart, X. Deng, E. Winward, and G. Dong, "Explicit model predictive control on the air path of turbocharged diesel engines," in Proceedings of the American Control Conference, 2013, pp. 5220-5225.

[22] E. Winward, J. Rutledge, J. Carter, A. Costall, R. Stobart, D. Zhao, and Z. Yang, "Performance testing of an electrically assisted turbocharger on a heavy duty diesel engine," in Proceedings of the 12th International Conference on Turbochargers and Turbocharging, 2016.

[23] Z. Yang, E. Winward, D. Zhao, and R. Stobart, "Three-input-threeoutput air path control system of a heavy-duty diesel engine," in Proceedings of the 8th IFAC International Symposium on Advances in Automotive Control, 2016.

[24] B. Bilgin, P. Magne, P. Malysz, Y. Yang, V. Pantelic, M. Preindl, A. Korobkine, W. Jiang, M. Lawford, and A. Emadi, "Making the case for electrified transportation," IEEE Transactions on Transportation Electrification, vol. 1, no. 1, pp. 4-17, 2015.

[25] N. Nagel and R. Lorenz, "Modeling of a saturated switched reluctance motor using an operating point analysis and the unsaturated torque equation," IEEE Transactions on Industry Applications, vol. 36, no. 3, pp. 714-722, 2000.

[26] P. Apkarian and D. Noll, "Nonsmooth $H_{\infty}$ synthesis," IEEE Transactions on Automatic Control, vol. 51, no. 1, pp. 71-86, 2006. 